\title{
Reconstruction of an abdominal wall defect following wide excision of metastatic squamous cell carcinoma at the percutaneous gastrostomy site in a head and neck cancer patient
}

\author{
Chenicheri Balakrishnan MD, Kristopher B Sugg BA, Christopher Vashi MD
}

\begin{abstract}
C Balakrishnan, KB Sugg, C Vashi. Reconstruction of an abdominal wall defect following wide excision of metastatic squamous cell carcinoma at the percutaneous gastrostomy site in a head and neck cancer patient. Can J Plast Surg 2006;14(3):181-183.

Cancer metastasis to an enterostomy site is a rare and serious complication. The incidence seems to be on the rise due to increased acceptance of the percutaneous endoscopic gastrostomy procedure. Because this may be associated with synchronous distant metastasis, full metastatic workup is required. Resections of these metastatic lesions require full-thickness abdominal wall reconstruction.
\end{abstract}

Key Words: Metastatic carcinoma at the percutaenous gastrostomy; Rectus myocutaneous flap
La reconstruction d'une anomalie de la paroi abdominale après la large excision d'un carcinome épidermoïde métastatique au foyer de la gastrostomie percutanée d'un patient atteint d'un cancer de la tête et du cou

\begin{abstract}
Une métastase cancéreuse à un foyer d'entérostomie est une complication rare et grave. L'incidence semble être en hausse, en raison de l'acceptation accrue de subir une gastrostomie endoscopique percutanée. Puisque ce phénomène peut s'associer à une métastase synchrone distante, un bilan métastatique complet s'impose. Après la résection de ces lésions métastatiques, il faut procéder à une reconstruction complète de toute l'épaisseur de la paroi abdominale.
\end{abstract}

$\mathrm{M}$ etastasis of head and neck cancer to the gastrostomy site is a rare but increasingly reported complication after percutaneous endoscopic placement of a gastrostomy tube. The management of these tumours involves resection of the abdominal wall and the area of the stomach. Reconstruction of the abdominal wall defects in these patients involves composite tissue to protect abdominal content from evisceration, infection and hernia formation. Pedicled myocutaneous or muscle flaps have been the reconstructive option of choice for these soft tissue defects with reconstruction of the abdominal fascia.

We report the case of a patient who underwent wide excision of head and neck carcinoma metastasis to the percutaneous endoscopic gastrostomy (PEG) site, where the abdominal wall was reconstructed using a vertical rectus abominis myocutaneous flap.

\section{CASE PRESENTATION}

A 50-year-old male patient underwent total laryngectomy with reconstruction for recurrent squamous cell carcinoma. He had an endoscopic gastrostomy tube placed before his resection to improve his nutritional status. His gastrostomy tube was removed once he was able to tolerate oral feeding. He subsequently presented to the hospital with swelling and pain at the PEG site (Figure 1). He underwent a computed tomography scan, which showed a solid tumour of the abdominal wall with no evidence of any metastatic disease. A fine needle aspiration biopsy confirmed the mass to be squamous cell carcinoma. He underwent wide resection of the tumour (Figure 2) and the

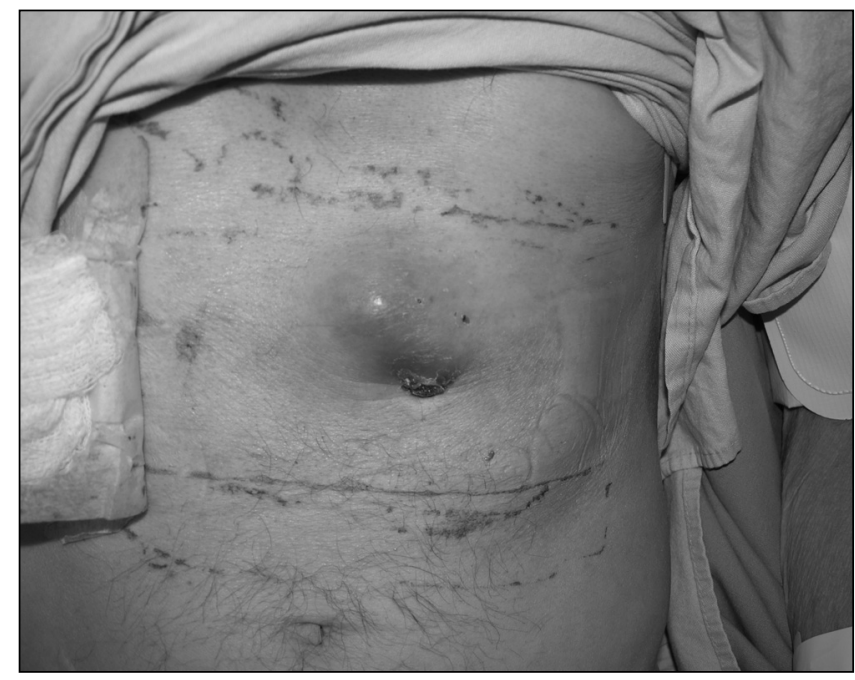

Figure 1) Metastatic tumour to the percutaneous endoscopic gastrostomy site

area of the stomach. Part of the left rectus abdominis muscle and the superior epigastric artery was sacrificed at the time of resection. The abdominal wall was reconstructed using a superiorly based rectus abdominis myocutaneous flap from the right side, where the anterior rectus sheath was used as fascial support with primary closure of the anterior rectus sheath (Figure 3). 


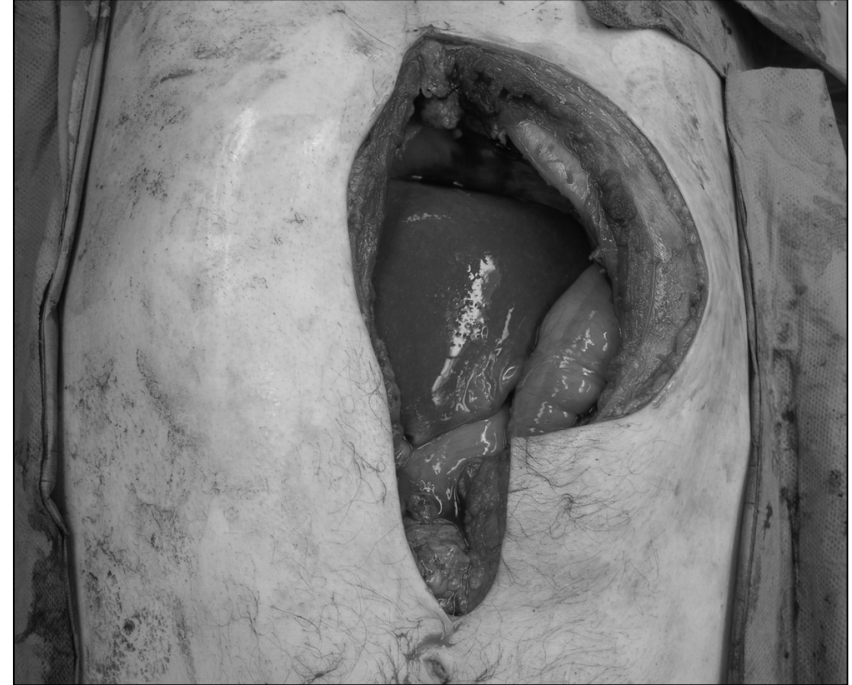

Figure 2) Abdomen following resection of a metastatic tumour to the percutaneous endoscopic gastrostomy site

\section{DISCUSSION}

Multimodality treatment for head and neck cancer using chemotherapy and radiation often produce significant mucositis and dysphagia. Patient and physician preferences have resulted in the increased use of PEG tubes as a safe and widely accepted alternate route for enteral feeding (1). However, this has resulted in increased reports of metastasis at the PEG site. PEG site metastases are iatrogenic complications of the PEG tube placement in patients with squamous cell carcinoma of the upper aerodigestive tract.

Cancer metastasis to a PEG tube exit site is a rare but serious complication. The presence of distant metastases is representative of the natural history of advanced head and neck malignancies. The mode of tumour spread to the gastrostomy site remains debatable. Hematogenous dissemination is a possible mechanism of metastasis, but direct implantation cannot be excluded. Studies carried out to determine the route of spread of the metastasis showed that at less than 10 months after using the 'pull' gastrostomy tube placement technique, only approximately one-quarter of the patients (four of 17) had synchronous distant metastatic disease; however, after 10 months, all 17 patients had synchronous distant metastatic disease (2). Because there is an increased incidence of reported cases of spread of head and neck cancer to the abdominal wall after PEG, some authors recommend a laparoscopic approach (3) and that the 'pull' method be deferred until after extirpation of the head and neck tumour (4). The use of laparoscopic gastrostomy tube placement using the open or the 'push' technique in patients with head and neck cancer has been suggested to prevent direct implantation of malignant cells into enteral access site (5). Although the incidence of abdominal wall metastasis after PEG tube placement for head and neck cancer is unknown, when these cancers metastasize to gastrostomy site, patient survival appears limited even after extensive resection (4).

Abdominal wall reconstruction is indicated after tumour resection, trauma or removal of infected mesh. These defects can be partial or complete. Because the abdominal wall protects the vital intra-abdominal organs, reconstruction of the

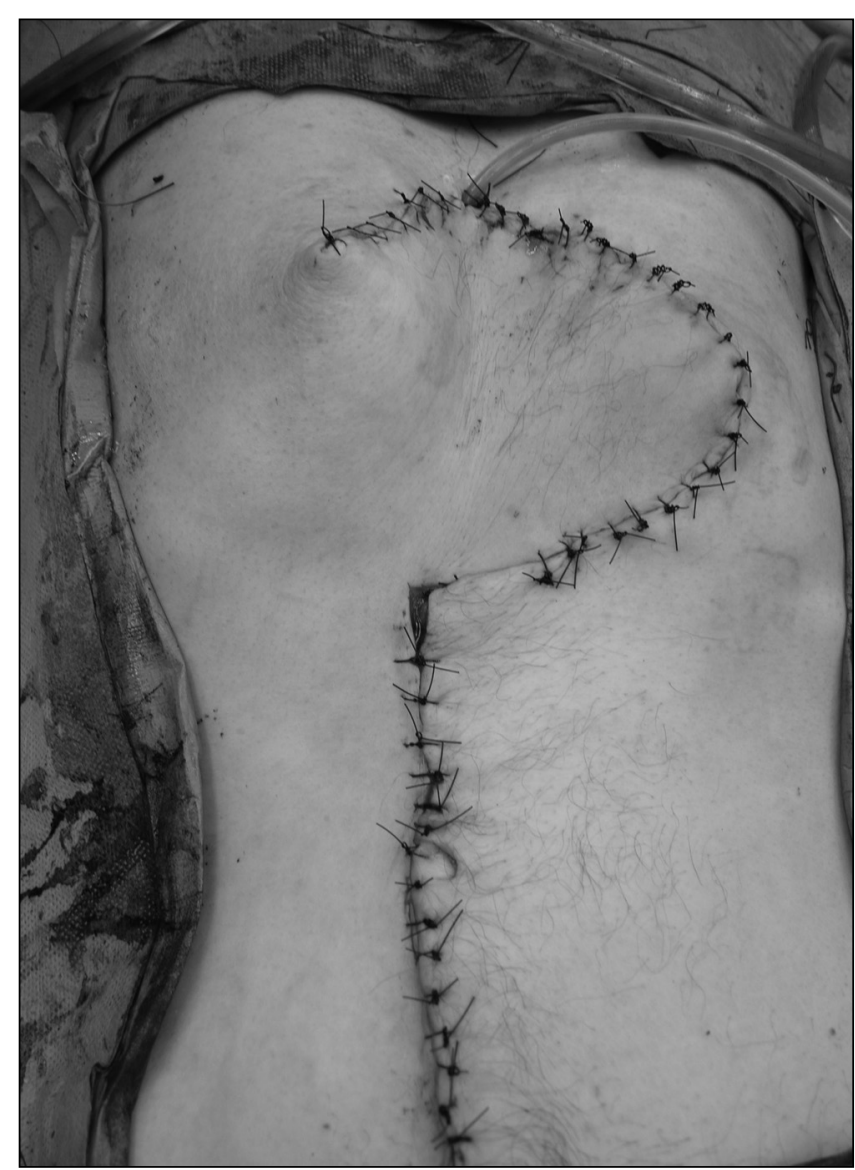

Figure 3) Reconstruction using a vertical rectus myocutaneous flap

abdomen carries a higher morbidity rate than other cutaneous reconstructive procedures (6). Reconstruction of full-thickness defects of the abdominal wall is a difficult problem. Skin grafts can be used over the granulating peritoneal surface, although reconstruction of a competent abdominal wall may be necessary later. Complications of the abdominal wall defects lead to herniation, which may incarcerate or even strangulate through the fascial defects. In some cases, the defects are large enough that the risk of strangulation is low, as is the benefit of surgery.

The abdominal wall defect is classified as midline or lateral, and belonging to the upper middle or lower one-third of the abdomen. Local flaps have limited value for midline defects due to their limited arc of rotation. Distant flaps are usually harvested for the lateral position and are difficult to advance to midline. Their use as a first-line option for reconstruction of large, midline defects should be discouraged (7).

A myocutaneous flap provides skin, subcutaneous tissue and fascia for the reconstruction of abdominal wall defects. It is the preferred reconstructive option following tumour resection, debridement of contaminated wounds and as soft tissue coverage over fascial repairs with prosthetic material. Proper flap design and tailoring of the flap to fit the tissue defect results in correction of the deformity and optimal function. The vascularized tissue provides protection for vital organs and increases resistance to infection. The rectus abdominis muscle is the workhorse of the abdominal wall reconstruction. Dual blood supply from the superior and inferior epigastric arteries allows the rectus abdominis muscle to be based superiorly or 
caudally. It can be used with or without a skin paddle to reconstruct the wounds of the upper and lower quadrants of the abdomen, as well as the suprapubic and umbilical areas. The only area in which this flap is less suitable is in the epigastrium, due to the arc of rotation.

\section{REFERENCES}

1. Lee DS, Mohit-Tabatabai MA, Rush BF Jr, Levine C. Stomal seeding of head and neck cancer by percutaneous endoscopic gastrostomy tube placement. Ann Surg Oncol 19952:170-3.

2. Adelson RT, Ducic Y. Metastatic head and neck carcinoma to a percutaneous endoscopic gastrostomy site. Head Neck 2005;27:339-43.

3. Bhama JK, Hass MK, Fisher WE. Spread of a pharyngeal cancer to the abdominal wall after percutaneous endoscopic gastrostomy. Surg Laparosc Endosc Percutan Tech 2001;11:375-8.

4. Meurer MF, Kenady DE. Metastatic head and neck carcinoma in a percutaneous gastrostomy site. Head Neck 1993;15:70-3.

\section{SUMMARY}

In the present patient, resection of the abdominal wall resulted in removal of part of the left rectus abdominis muscle and the superior epigastric artery. A myocutaneous flap based on the right superior epigastric artery was used to reconstruct the defect.

5. Tucker AT, Gourin CG, Ghegan MD, Porubsky ES, Martindale RG, Terris DJ. 'Push' versus 'pull' percutaneous endoscopic gastrostomy tube placement in patients with advanced head and neck cancer. Laryngoscope 2003;113:1898-902.

6. Hobar PC, Rohrich RJ, Byrd HS. Abdominal-wall reconstruction with expanded musculofascial tissue in a posttraumatic defect. Plast Reconstr Surg 1994;94:379-83.

7. Rorich RJ, Lowe JB, Hackrey FL, Bowman JL, Hobbar PC. An algorithm for abdominal wall reconstruction. Plast Reconstr Surg 2000;105:202-16. 